\title{
Brackish Water Treatment into raw water using Moringa oleifera leaves as an adsorber at Habibie Mustafa College, Keramat Kubah Village, Tanjungbalai Town
}

\author{
Desi Ardilla ${ }^{1 *}$, Khairunnisa Rangkuti ${ }^{2}$, Muhammad Taufik ${ }^{3 *}$ \\ ${ }^{1}$ Agricultural Technology Department, Universitas Muhammadiyah Sumatera Utara, Medan, \\ Indonesia \\ ${ }^{2}$ Agribusiness Department, Universitas Muhammadiyah Sumatera Utara, Medan, Indonesia \\ ${ }^{3}$ Chemistry Department, Faculty of Mathematic and Natural Science, Universitas Sumatera \\ Utara, Medan
}

*Email: desiardilla@umsu.ac.id; Muhammad.taufik@usu.ac.id

\begin{abstract}
This work aims to provide raw water from brackish water by reducing the salt content in brackish water to fresh water using the column method. Moringa leaves were chosen as the adsorber considering their high availability in partner locations. The location chosen was Habibie Mustafa's college in Tanjungbalai, North Sumatra. Brackish water treatment equipment is designed using a distillation system. In the column refining, the filter tubes used are made using PVC pipe with a height of $45 \mathrm{~cm}$ (Moringa leaves), a height of $35 \mathrm{~cm}$ (sand), and a height of $25 \mathrm{~cm}$ (charcoal). Each filter media in the tube is limited by using a palm fiber. The use of fibers is used as a barrier between the filter media so that the filter media remains in its position during the filtration process so that there is no mixing of the filter media in the filter tube. The results obtained are clean water that can be consumed according to drinking water quality standards. The results obtained were raw water with TDS specifications $=405 \mathrm{mg} / \mathrm{L}$, turbidity $4 \mathrm{NTU}$, sulfate $=240 \mathrm{mg} / \mathrm{L}$ zinc $=2 \mathrm{mg} / \mathrm{L}$, and $\mathrm{Mn}=0.35 \mathrm{mg} / \mathrm{L}$. The results obtained are still on the threshold of drinking water quality standard requirements by the Minister of Health of the Republic of Indonesia Number: 492 / Menkes / Per / IV / 2010 concerning drinking water quality requirements..
\end{abstract}

Keywords: Brackish water, brackish water, raw water, filter, Moringa leaves.

\begin{abstract}
Abstrak
Kegiatan ini bertujuan untuk menyediakan air baku dari air payau melalui penurunan kadar garam dalam air payau menjadi air tawar dengan menggunakan metode kolom. Daun kelor dipilih sebagai adsorber mengingat keterdapatanya yang tinggi di Lokasi mitra. Lokasi yang dipilih adalah perguruan Habibie Mustafa di Tanjungbalai Sumatera Utara. Alat pengolahan air payau dirancang dengan menggunakan sistem penyulingan. Pada penyulingan kolom, tabung filter yang digunakan dibuat dengan menggunakan pipa pvc $3 / 4$ dengan ketinggian $45 \mathrm{~cm}$ (daun kelor), ketinggian $35 \mathrm{~cm}$ (pasir), dan ketinggian $25 \mathrm{~cm}$ (arang). Masing- masing media filter di dalam tabung dibatasi dengan menggunakan ijuk. Penggunaan ijuk digunakan sebagai pembatas antara media filter agar media filter tetap pada posisinya ketika terjadi proses filtrasi sehingga tidak terjadi pencampuran media filter di dalam tabung filter. Hasil yang diperoleh adalah air bersih yang dapat dikonsumsi sesuai dengan baku mutu air minum. Hasil yang diperoleh adalah air baku dengan spesifikasi TDS $=405 \mathrm{mg} / \mathrm{L}$, kekeruhan $4 \mathrm{NTU}$, sulfat $=240 \mathrm{mg} / \mathrm{L}$ seng $=2 \mathrm{mg} / \mathrm{L}$, dan $\mathrm{Mn}=0,35 \mathrm{mg} / \mathrm{L}$. Hasil yang diperoleh masih diambang batas persyaratan baku mutu air minum oleh Menteri Kesehatan RI Nomor: 492/Menkes/Per/IV/2010 tentang persyaratan kualitas air minum.
\end{abstract}

Kata Kunci: Air payau, Air payau, Air baku, filter, daun kelor. 


\section{PENDAhUluan}

Air merupakan unsur penting dalam kehidupan manusia. Seseorang tidak dapat bertahan hidup tanpa air, oleh karena itu air merupakan salah satu penopang hidup bagi manusia. Ketersediaan air di dunia ini begitu melimpah ruah, namun yang dapat di konsumsi manusia untuk keperluan air minum sangatlah sedikit. Selain itu, kecenderungan yang terjadi sekarang ini adalah berkurangnya ketersediaan air bersih itu hari demi hari. Di Indonesia sendiri di perkirakan, sebanyak 60 persen sungainya, terutama di Sumatera, Jawa, Bali dan Sulawesi, tercemar berbagai limbah. Di ramalkan 2025 nanti hampir dua pertiga penduduk dunia akan tinggal di daerah-daerah yang mengalami kekurangan air (Nisala et al., 2020). Air tanah merupakan air yang berada di bawah permukaan bumi yang terdapat pada ruang ruang antar butir ataupun celah celah tanah. Air tanah yang digunakan oleh masyarakat harus memiliki kriteria kesehatan sehingga dapat digunakan masyarakat dalam kehidupan sehari hari termasuk sebagai baku air minum (Arif, 2015).

Desalinasi merupakan proses pengurangan kadar garam pada air laut, air payau, atau air limbah. Proses desalinasi biasanya digunakan untuk mengolah air laut menjadi air bebas mineral yang dapat dikonsumsi oleh manusia (Apori et al., 2020). Pada Kegiatan ini, daun kelor diaktivasi akan menurunkan salinitas air laut. Penggunaan material ini digunakan sebagai alternatif yang dapat digunakan untuk memperbaiki kualitas air payau menjadi air baku dengan biaya yang lebih murah dan proses lebih sederhana yakni menggunakan metode pertukaran ion (Aziz et al., 2015). Pada proses ini, Natrium Hidroksida $(\mathrm{NaOH})$ digunakan dalam proses pembasaan karena natrium hidroksida dikenal sebagai basa yang mampu melarutkan senyawa yang bersifat anorganik serta baik digunakan untuk melarutkan sampel batuan (Punia et al. 2017). Eksplorasi dan aktivasi daun kelor merupakan proses untuk menaikkan kapasitas adsorbsinya sehingga diperoleh sifat yang diinginkan sesuai dengan penggunaanya (Vieira et al., 2020). Tujuan aktivasi adalah untuk menghasilkan luas permukaan yang lebih luas melalui pembentukan struktur berpori serta menghilangkan senyawa-senyawa pengotor dan mengatur kembali letak atom yang dipertukarkan (Nisala et al., 2020).

Air laut merupakan air yang berasal dari lautan (Nisala et al., 2020). Air laut berbeda denga air tawar sebab air ini mengandung garam, oleh karena itu rasanya asin. Tingkat kandungan garam pada air laut disebut dengan salinitas. Salinitasnya rata-rata sekitar 35 parts per thousand (ppt), yang artinya setiap $1 \mathrm{~kg}$ air mengandung 35 gram garam terlarut. Garam terlarut ini terdiri dari 6 ion utama, yaitu Klorida (CL-), Natrium (Na+), Sulfat (SO24-), Magnesium (Mg2+), Kalsium $(\mathrm{Ca} 2+)$, dan Kalium $(\mathrm{K}+)$ (Alshammari, 2020). Natrium dan Klorida merupakan ion garam paling dominan terkandung di laut, oleh karena itu garam dapur (Natrium Klorida/ $\mathrm{NaCl}$ ) banyak diperoleh dari air laut. Air laut memiliki kadar garam rata- rata 3,5\% yang artinya dalam 1 liter $(1000 \mathrm{~mL})$ air laut terdapat 35 gram $\mathrm{NaCl}$. Air laut memiliki kadar garam karena bumi dipenuhi dengan garam mineral yang terdapat di dalam batu-batuan misalnya natrium, kalium dan kalsium. Apabila air sungai mengalir ke lautan maka air tersebut membawa garam. Ombak laut yang terjadi pada pantai juga menghasilkan garam pada batu-batuan. Zat terlarut meliputi garam-garam anorganik sementara senyawa-senyawa organik berasal dari organisme hidup dan gas-gas terlarut (Apori et al., 2020). Salinitas adalah tingkat keasinan atau kadar garam terlarut dalam air serta salinitas juga dapat mengacu pada kandungan garam dalam tanah (Pine \& Claude E. Boyd, 2011). Dengan demikian, penyulingan yang dilakukan saat ini belum efektif untuk menyaring air tawar dari air payau sehingga digunakan alternative menggunakan daun kelor teraktivasi sebagai adsorber.

Penelitian tentang pengelolaan air bersih telah banyak dilakukan oleh beberapa peneliti. Pengolahan air payau menjadi air bersih telah dilakukan menggunakan filter zeolite dan bentonit (Nisala et al., 2020). Metode yang digunakan adalah metode adsorpsi dengan membandingkan material zeolit dan bentonit dengan Hydraulic Loading Rate (HLR) 0,25 m/jam. Filter zeolit yang digunakan sebagai adsorben memiliki efektivitas penurunan konsentrasi TDS mencapai 41,78\%, salinitas $40 \%$, natrium $72,51 \%$, sulfat $43,36 \%$, HCO3 53,14\%, kalium 88,89\% dan kesadahan $36,88 \%$. Filter bentonit sebagai adsorben memiliki efektivitas penurunan konsentrasi TDS 
mencapai 49,4\%, salinitas 46,67\%, natrium 75,10\%, sulfat 45,80\%, HCO3 37,96\%, kalium $11,11 \%$ dan kesadahan $41,87 \%$. Sehingga filter zeolite lebih optimal dibandingan filter bentonit. Desalinasi air payau menggunakan energy solar dengan parabolic through telah diteliti. Efisiensi destilasi ekperimen mencapai $18,12 \%$. Volume yang dihasilkan sebesar 2,494 L/m2 dalam satu hari dengan laju destilasi 0,312 L/m2. Kemampuan penyisihan TDS dan DHL sebesar 99,9\% (Alshammari, 2020). Namun metode ini memiliki kelemahan yakni membutuhkan biaya yang besar. Metode Reverse osmosis (RO) dalam pengolahan air laut menjadi air bersih juga telah dilakukan. Namun metode ini masih sangat kompleks dan juga membutuhkan biaya yang besar (Apori et al., 2020). Tujuan kegiatan ini adalah untuk melaksanakan penyuluhan dan sosialisasi pengolahan sumber air baku dari air payau kepada masyarakat.

\section{METODE PELAKSANAAN}

\subsection{Alat dan Bahan}

Alat yang digunakan adalah ayakan $200 \mathrm{Mesh}$, Lem, Tray/baki, Kolom, oven, Neraca Analitik, Beaker glass, Alu dan Mortar, Hot Plate, Desikator, Cawan Porselen, Pipa PVC 3/4 inchi, Socket PVC drat luar $3 / 4$, Fauset PVC, drat, dan ijuk

\subsection{Lokasi Pengabdian Masyarakat}

Pengabdian Masyarakat dilaksanakan pada Perguruan Habibie Mustafa Kelurahan Keramat Kubah Kecamatan Sei Tualang Raso Kota Tanjungbalai. Lokasi pengabdian Masyarakat dapat dilihat pada Gambar 2.1. berikut ini :

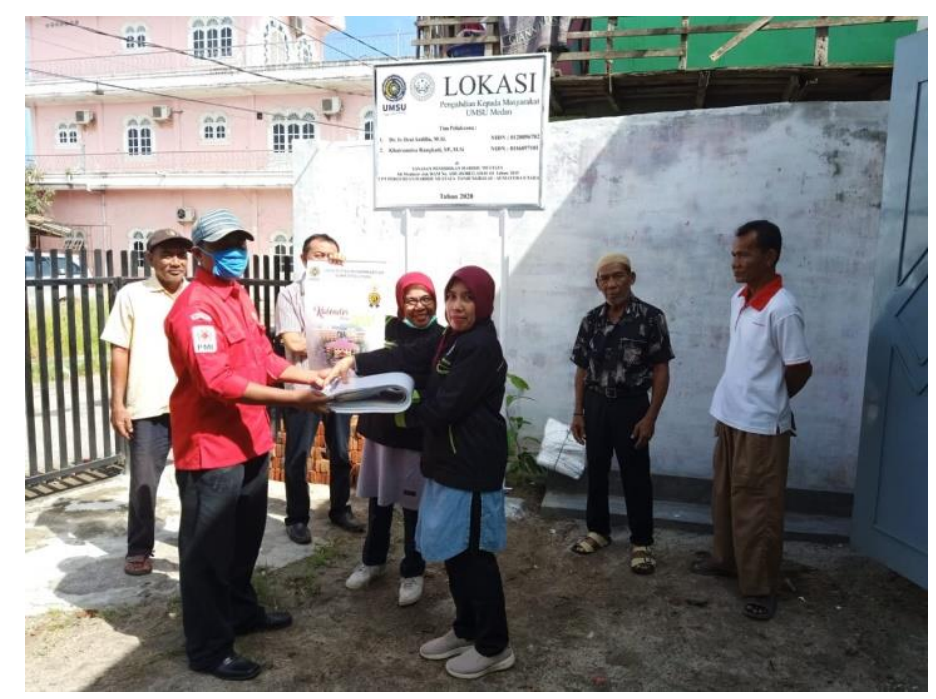

Gambar 2.1. Peta Lokasi Penelitian

Gambar 2.1. menunjukkan Peta lokasi Penelitian yang berada di Kota Tanjungbalai Sumatera Utara.

\subsection{Penyediaan of adsorbent dari daun kelor}

Sebanyak 50 gram daun kelor ditimbang dan dihaluskan dan diayak pada 200 mess, kemudian direndam dalam $250 \mathrm{ml} \mathrm{HCl} 6 \mathrm{M}$ selama 24 jam. Setelah itu daun kelor dinetralkan dengan aquadest. Kemudian dikeringkan dalam oven dengan suhu $120^{\circ} \mathrm{C}$ selama 6 jam. Daun kelor yang ditimbang kemudian dinetralkan dengan $\mathrm{NaOH} 4 \mathrm{M}$ dan dipanaskan. Setelah dikeringkan, larutan dimasukkan ke dalam tungku pada suhu $550^{\circ} \mathrm{C}$ selama 2 jam. Setelah dingin campuran ditambahkan bubuk $\mathrm{Al}$ dan $200 \mathrm{ml} \mathrm{0,02} \mathrm{mol} \mathrm{NaOH}$ dan diaduk dengan batang pengaduk magnet selama 30 menit dengan 
kecepatan $500 \mathrm{rpm}$. Penuaan dilakukan pada temperatur selama 12 jam waktu pemeraman. Setelah itu autoklaf dilakukan selama 2 jam pada suhu $110^{\circ} \mathrm{C}$, membentuk dua lapisan yaitu filtrat dan sedimen. Kemudian pisahkan dekantasi lumpur. Lumpur dicuci sampai pH larutan 7 (Okoya et al., 2020). Kristal yang sudah dicuci dikeringkan dalam oven selama 48 jam. Residu dikeringkan di dalam Tanur pada suhu $300^{\circ} \mathrm{C}$ selama $1 \mathrm{jam}$. Dianalisis komposisi daun kelor yang teraktivasi menggunakan XRF.

\subsection{Rancangan alat filtrasi}

Sistem filtrasi dimana tabung filter yang digunakan dibuat dengan menggunakan pipa pvc 6" dengan tinggi 1 meter sebanyak 2 buah. Tabung filter yang pertama berisi media filter pasir halus dengan ketinggian $50 \mathrm{~cm}$ dan zeolit dengan ketinggian $40 \mathrm{~cm}$. Tabung filter yang kedua berisi media filter daun kelor yang diaktivasi dengan ketinggian $45 \mathrm{~cm}$. Masing - masing media filter didalam tabung filter dibatasi dengan menggunakan kawat. Penggunaan kawat digunakan sebagai pembatas antara media filter.

\subsection{Proses Aliran Filter}

Jenis aliran yang digunakan yaitu aliran downflow dimana aliran air payau akan mengalir dari atas tabung menuju ke bawah tabung filter Aliran air didalam tabung filter dialirkan melalui pipa pvc berdiameter $3 / 4$ " yang terhubung melewati kedua tabung filter tersebut. Proses filtrasi dilakukan dengan cara membuka katup inlet (katup 1), membuka katup aliran filter, membuka katup outlet dan menutup katup aliran pencucian media filter yang terdapat pada alat pengololahan air payau. Jenis aliran yang digunakan adalah aliran downflow, dimana air payauakan mengalir dari atas menuju bawah tabung filter secara gravitasi.

\subsection{Proses penyaringan}

Dengan sistem penyaringan dari arah atas kebawah (downflow) dengan menggunakan gaya gravitasi, dapat memperlama waktu kontak antara air payau dan media filter pada tabung filter. Selain itu, sistem penyaringan downflow juga dapat memudahkan dalam proses backwash (Sörengård et al., 2020). Ketika air gambut masuk kedalam tabung filter melalui katup inlet, secara gravitasi air payau secara berurutan akan melewati media filter daun kelor hasil aktivasi. Ijuk digunakan agar daun kelor tidak ikut bersama aliran air. Debit air pengolahan yang dihasilkan oleh alat pengolahan air gambut harus mencukupi kebutuhan air yang digunakan sebagai sumber air untuk air minum di Lokasi Pengabdian Masyarakat.

\subsection{Analisis air baku} Mn.

Analisis air baku yang dihasilkan dilakukan dengan pengujian TDS, kekeruhan, sulfat, seng, dan

\section{HASIL DAN PEMBAHASAN}

Sebelum sosialisasi program PKM dilakukan, terlebih dahulu bermusyawarah di Lokasi Pengabdian Masyarakat untuk berdiskusi proses kegiatan yang dilakukan di Perguruan Habibie Mustafa Kelurahan Keramat Kubah Kecamatan Sei Tualang Raso Kota Tanjungbalai - Sumatera Utara. Acara dimulai dengan beramah tamah dengan masyarakat sekitar dan sebagian pengurus pada Perguruan Habibie Mustafa Kelurahan Keramat Kubah Kecamatan Sei Tualang Raso Kota Tanjungbalai - Sumatera Utara kemudian barulah sosialisasi PKM disampaikan bagaimana memanfaatkan daun kelor dan proses pengolahan air payau menjadi air baku dengan menggunakan teknologi sederhana dan murah. Gambar 3.1. menujukkan Tim di lokasi kegiatan. 


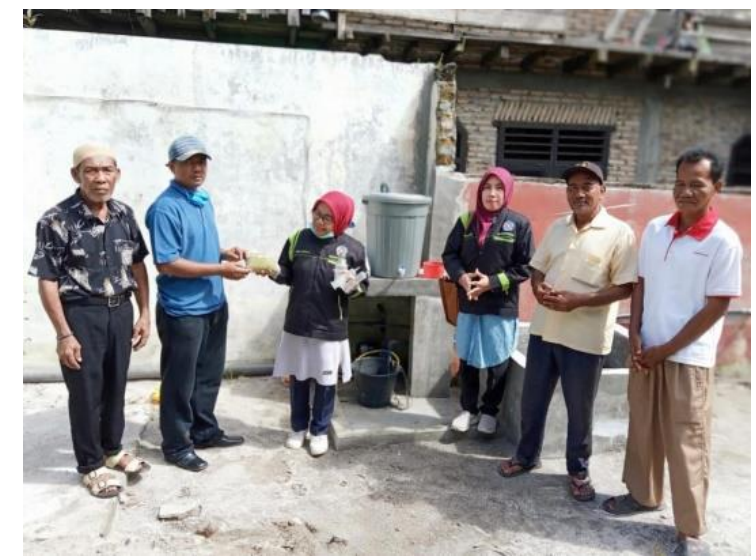

Gambar 3.1. Tim PKM ikut pada acara kegiatan pengajian di Lokasi

\subsection{Komposisi daun kelor setelah diaktivasi}

Daun kelor yang digunakan sebagai adsorbent dianalisis komposisinya dengan menggunakan XRF dan data yang dihasilkan seperti pada Tabel 3.1. berikut ini :

Tabel 3.1. Kandungan daun kelor setelah aktivasi

\begin{tabular}{llc}
\hline No & Jenis Unsur & $\begin{array}{c}\text { Komposisi } \\
\text { Daun kelor } \\
(\%)\end{array}$ \\
\hline 1 & $\mathrm{Al}$ & 41.461 \\
2 & $\mathrm{Si}$ & 14.986 \\
3 & $\mathrm{P}$ & 0.534 \\
4 & $\mathrm{Ag}$ & 1.406 \\
5 & $\mathrm{Sb}$ & 2.160 \\
6 & $\mathrm{Zr}$ & 0,353 \\
7 & $\mathrm{Ti}$ & 2.219 \\
8 & $\mathrm{Fe}$ & 32.642 \\
9 & $\mathrm{As}$ & 0.113 \\
10 & $\mathrm{Zn}$ & 0.152 \\
11 & $\mathrm{Co}$ & 0.393 \\
12 & $\mathrm{Mo}$ & 0,032 \\
13 & $\mathrm{~V}$ & 0.114 \\
14 & $\mathrm{Ni}$ & 0.067 \\
15 & $\mathrm{Mg}$ & 0.057 \\
16 & $\mathrm{~S}$ & 1.986 \\
\hline
\end{tabular}

Tabel 3.1. menunjukkan komposisi daun kelor setelah aktivasi. Berdasarkan data XRF diatas, maka dapat diketahui bahwa daun kelor yang digunakan sebagai adsorben pada kegiatan ini dapat digunakan dengan kandungan terbesar adalah Al sebesar $41.461 \%$. 
Adsorpsi merupakan dimana molekul molekul fluida menyentuh dan melekat pada permukaan padatan. Pada peristiwa ini, adsorpsi merupakan fenomena fisik yang terjadi saat molekul molekul gas atau cair dikontakkan dengan suatu permukaan padatan dan sebagian dari molekul molekul tesebut mengenbun pada permukaan padatan tersebut. Proses adssrpsi terjadi apabila permukaan padatan dan molekul molekul gas atau cairan dikontakkan. Pada kegiatan ini, daun kelor yang telah diaktivasi digunakan sebagai adsorber dan akan mengikat secara fisik komponen komponen yang terdapat pada air payau, kemudian air akan dimurnikan dengan cara gravitasi dengan menghasilkan $\mathrm{pH}$ netral $=7$.

\subsection{Analisis Air hasil filtrasi}

Air hasil filtrasi menggunakan daun kelor dianalisis sifat fisika kimia dan diperoleh hasil seperti pada Tabel 3.2. berikut ini :

Tabel 3.2. Hasil analisis air hasil filtrasi

\begin{tabular}{ccc}
\hline No. & Parameter & Hasil \\
\hline 1 & TDS & $405 \mathrm{mg} / \mathrm{L}$ \\
2 & kekeruhan & $4 \mathrm{NTU}$ \\
3 & sulfat & $240 \mathrm{mg} / \mathrm{L}$ \\
4 & seng & $2 \mathrm{mg} / \mathrm{L}$ \\
5 & $\mathrm{Mn}$ & $0,35 \mathrm{mg} / \mathrm{L}$ \\
\hline
\end{tabular}

Tabel 3.2. menunjukkan hasil analisis dari air bersih yang diperoleh di lokasi pengambilan sampel. Hasil yang diperoleh adalah air baku dengan spesifikasi TDS $=405 \mathrm{mg} / \mathrm{L}$, kekeruhan $4 \mathrm{NTU}$, sulfat $=$ $240 \mathrm{mg} / \mathrm{L}$ seng $=2 \mathrm{mg} / \mathrm{L}$, dan $\mathrm{Mn}=0,35 \mathrm{mg} / \mathrm{L}$. Hasil yang diperoleh masih berada diambang batas persyaratan baku mutu air minum oleh Menteri Kesehatan RI Nomor: 492/Menkes/Per/IV/2010 tentang persyaratan kualitas air minum.

\subsection{Sosialisai kepada masyarakat}

Sosialisasi kepada masyarakat dilakukan melalui demonstrasi tentang bagaimana mengolah air payau menjadi air baku. Mitra terlibat secara langsung dalam setiap proses dimulai dari persiapan bahan baku daun kelor, pasir, arang sampai proses pengolahan menjadi air bersih. Air bersih yang diperoleh dianalisis di Laboratorium THP UMSU. Sosialisasi tentang penyediaan air baku dari air payau kepada mitra tentang teknologi zero waste melalui penyediaan air baku yang bersumber dari air payau. Filter dimodifikasi sehingga akan diperoleh rendemen air bersih pada penyulingan air payau dengan metode kolom. Pada penyulingan kolom, tabung filter yang digunakan dibuat dengan menggunakan pipa pvc 3/4" ketinggian $45 \mathrm{~cm}$ dan dengan daun kelor pada ketinggian $35 \mathrm{~cm}$ dan pasir dengan ketinggian $30 \mathrm{~cm}$ serta untuk arang dengan ketinggian $25 \mathrm{~cm}$. masing- masing media filter di dalam tabung dibatasi dengan menggunakan ijuk. Penggunaan ijuk digunakan sebagai pembatas antara media filter agar media filter tetap pada posisinya ketika terjadi proses filtrasi sehingga tidak terjadi pencampuran media filter di dalam tabung filter. Maka hasil akhir yang diperoleh adalah air bersih yang siap dikonsumsi sesuai dengan persyaratan baku mutu air minum oleh Menteri Kesehatan RI Nomor: 492/Menkes/Per/IV/2010 tentang persyaratan kualitas air minum.

\section{KESIMPULAN}

Pengolahan air payau menjadi air baku dapat dilakukan menggunakan metode filtrasi menggunakan daun kelor (Moringa oleifera) sebagai adsorber. Hasil yang diperoleh adalah air baku dengan spesifikasi TDS $=405 \mathrm{mg} / \mathrm{L}$, kekeruhan $4 \mathrm{NTU}$, sulfat $=240 \mathrm{mg} / \mathrm{L}$ seng $=2 \mathrm{mg} / \mathrm{L}$, dan $\mathrm{Mn}=$ $0,35 \mathrm{mg} / \mathrm{L}$. Hasil yang diperoleh masih diambang batas persyaratan baku mutu air minum oleh Menteri Kesehatan RI Nomor: 492/Menkes/Per/IV/2010 tentang persyaratan kualitas air minum. 


\section{UCAPAN TERIMAKASIH}

Penulis mengucapkan terima kasih kepada Rektor Universitas Muhammadiyah Sumatera Utara atas dana penelitian Pengabdian Masyarakat melalui Skema Program Kemitraan Masyarakat Tahun 2020.

\section{DAFTAR PUSTAKA}

Alshammari, M. S. (2020). Assessment of Sewage Water Treatment Using Grinded Bauxite Rock as a Robust and Low-Cost Adsorption. Journal of Chemistry, 2020(1), 1-5.

Apori, S. O., Atiah, K., Hanyabui, E., \& Byalebeka, J. (2020). Moringa oleifera Seeds as a a Low Cost Biosorbent for Removing Heavy Metals from wastewater. STED Journal, 2(May), 45-52. https://doi.org/10.7251/STED2002045O

Arif, A. (2015). Pengaruh Bahan Kimia terhadap Penggunaan Pestisida Lingkungan. JF FIK Uinam, $3(4), 134-143$.

Aziz, N. A. A., Jayasuriya, N., \& Fan, L. (2015). Adsorption Study on Moringa Oleifera Seeds and Musa Cavendish as Natural Water Purification Agents for Removal of Lead, Nickel and Cadmium from Drinking Water Adsorption Study on Moringa Oleifera Seeds and Musa Cavendish as Natural Water Purification Age. IOP Conference Series: Materials Science and Engineering PAPER, 136(1), 1-9. https://doi.org/10.1088/1757-899X/136/1/012044

Nisala, Zaman, B., \& Sudarno. (2020). Natural Treatment of Desalination Process for Brackish Water. IOP Conf. Series: Earth and Environmental Science, 448(1), 1-6. https://doi.org/10.1088/17551315/448/1/012100

Okoya, A. A., Olaiya, O. O., Akinyele, A. B., \& Ochor, N. O. (2020). Efficacy of Moringa oleifera Seed Husk as Adsorptive Agent for Trihalomethanes from a Water Treatment Plant in Southwestern , Nigeria. Journal of Chemistry, 2020(1), 1-11.

Pine, H. J., \& Claude E. Boyd. (2011). Stream Salinization by Inland Brackish-Water Aquaculture This article was downloaded by: [ Auburn University ] Access details : Access Details : [ subscription number 930495794 ] North American Journal of Aquaculture Stream Salinization by Inland Brackis. North American Journal OfAquaculture 73:107-113, 73(01), 107-113. https://doi.org/10.1080/15222055.2011.545580

Punia, J., Singh, R., Kumari, S., \& Pandit, G. N. (2017). Phytochemical Investigations and Biological Potential of Moringa oleifera Pods JYOTI. Asian Journal of Chemistry, 29(6), 1341-1346.

Sörengård, M., Franke, V., Tröger, R., \& Ahrens, L. (2020). Losses of poly- and perfluoroalkyl substances to syringe filter materials. Journal of Chromatography A, 1609(J. Chromatogr. A), 17. https://doi.org/10.1016/j.chroma.2019.460430

Vieira, L. M., Silva, A. C., Neto, J. C. B. A., Paiva, S. C., Takaki, G. M. C., \& Messias, A. S. (2020). Use of Moringa Oleifera for Adsorption of Chemical Elements from the Mangrove Sediment. International Journal of Research Studies in Science, Engineering and Technology, 7(6), 1-7. 